\title{
The impact of transport infrastructure projects on sustainable development within a major logistics gateway in North West England
}

\author{
Dimitrios PARASKEVADAKIS ${ }^{*}$, Alan BURY ${ }^{*}$, Jin WANG ${ }^{1}$, Jun REN ${ }^{1}$, Stephen BONSALL ${ }^{1}$ and \\ Ian JENKINSON ${ }^{1}$ \\ 1 Liverpool John Moores University, School of Engineering and Maritime Operations, \\ Logistics Offshore and Marine Research Institute (LOOM), Liverpool, UK
}

\begin{abstract}
In the North West of England the issue of a perceived infrastructure gap is of increasing concern. Investment needs to be made to improve the transport infrastructure of the region if it is to be expected to promote the development of its own regional logistics gateway. Funding tools have been set up to address the challenges arising from the imbalance in infrastructure development that exists between regions in the north of the United Kingdom and those in the south. For regions with well developed economies the outlook is promising as the availability of modern transport infrastructure looks set to improve. However, some sources believe that the development of new transport infrastructure will have a negative impact upon sustainable development. It is expected that this will occur in a range of both direct and indirect ways. As a result, it is critical that planning for the creation of new intermodal transport infrastructure, or the upgrading of that which already exists, takes into account the impact that these developments will have on the sustainable development of the host region. A scenario based development methodology is proposed in this paper. It was developed to provide a way to identify potential scenarios that may arise within a given region as a result of transport infrastructure projects. To create significant scenarios the methodology is dependent on the availability of a sufficient quantity of quality data. For this paper that data was collected through a focus group composed of stakeholders from the region in question. This was further supported by the performance of an impact survey using the same group of stakeholders.
\end{abstract}

Key words-Multi-modal logistics, Gateways North West England, Focus Group, Impact Survey, Scenarios.

\section{INTRODUCTION}

The need for the logistics industry to contribute towards sustainable development is a global necessity. It is believed that this contribution can be made in three ways. Firstly by encouraging modal shift, secondly by logistics businesses making their operations and premises more efficient and thirdly by formalizing the development of more sustainable logistics gateways aimed at improving the service quality of the available transport infrastructure. The human population is growing and the majority of these people are living in metropolitan areas that account for the generation of high concentrations of greenhouse gases. The most populous regions contain heavy concentrations of multiply layered logistics and transport operations alongside other urban functions [1]. Although these local logistics arrangements are organized to meet the needs of the people living in their area they rely heavily on the global logistics industry.

Reducing the levels of emissions produced by the transport sector requires a better modal mix, more synergies between the private and the public sectors and a coordinated transnational approach. For the provision of transport infrastructure to be adequate in the long term, good planning, the selection of priority projects on which to focus and the evaluation of important factors needs to be performed. Some of these factors will relate to reducing levels of Carbon Dioxide $\left(\mathrm{CO}_{2}\right)$ emissions and protecting communities within the gateways from the environmental impacts of the already substantial amounts of $\mathrm{CO}_{2}$ that are being emitted. Co-modality supports initiatives associated with enhancing "greener transport" as it aims to achieve optimal sustainable scenarios in freight movement within regional logistics gateways. The vision of co-modality calls for 
the combination of different modes of transport with a view to optimising the use of the existing transport systems to deliver a more sustainable use of the available resources [2].

This concept emphasizes the need to adopt a set of wider objectives covering commercial, monetary and sustainable growth issues. Based on this concept infrastructure planning should be shaped accordingly at both national and international levels to provide a combined approach to future service quality provision.

The use of alternative modes of transport is very high on the agenda of the freight transport industry. The level of congestion is continuously rising and stakeholders are struggling to deliver greener solutions. Modal shift needs to be realised through the promotion of intermodal transport at all levels of the public and private sectors. Intermodal freight transport is perceived as being the best solution for the integration of the regional transportation systems. Such integration should take in to account the needs of the transport and supply chain industries [3]. The national borders that exist between different regions (such as in Europe) provide restrictions to the provision of an interoperable and seamless transportation service. This causes limitations to the quality and environmental impact of improvements that are delivered in leading regions. Awareness of the benefits of intermodal transport along with the availability of suitable infrastructure is critical for modal shift to be achieved across a broad area.

\section{CURRENT EVALUATION METHODOLOGIES OF TRANSPORT INFRASTRUCTURE PERFORMANCE}

It is widely agreed that improper planning and implementation of an infrastructure project may have adverse effects on the economy and the environment of a region. Geographical Information Systems (GIS) are used to capture and map trends of relevance to a geographical area (Bury et al., 2014). An appreciation of these dynamics is required in order to plan the provision of transport infrastructure that will be required to achieve sustainable development. In some cases an investment in infrastructure can pose a threat to the communities that will be directly affected by it. Therefore it is imperative that a performance assessment is carried out before, during and after the planning phase in order to measure the positive or negative impact that a transport infrastructure project may have against a set of different socio economic and environmental future scenarios [4]. There are a number of different methodologies for the evaluation of the impact that a project may have in the short and long term from an economic, social and environmental perspective. The majority of these methodologies focus primarily on the performance measurement that a project has within the economic, social and environmental dimensions only, without taking into consideration how the project will provide a sustainable balance between them. This lack of focus has led, in the last few years, to the need for the adoption of an integrated methodology with emphasis on the creation of balance between these different dimensions and also on sustainable development when an infrastructure project is planned. Another downside to the conventional modelling and evaluation methodologies is that they do not consider of the relationships that exist between the performance dynamics of an infrastructure project. This is one of the primary reasons that an understanding of these performance parameters should have a high priority in all stages of a project's implementation particularly for those that require increased funding and long periods of implementation time.

\section{INTEGRATION OF METHODOLOGY FOR THE EVALUATION OF CRITICAL PRIORITY TRANSPORT INFRASTRUCTURE PROJECTS}

Investments in transport infrastructure and regional economic development are closely interrelated. As a result they can be quite complicated. This belief is also justified by the findings of recent research studies which explored the linkage between transport infrastructure investments and economic growth [5]. The benefits of these investments are expected to be evident both at a national and international level. However, in some cases, one geographical area may not have received the same level of investment as another. Therefore, there has been a growing interest over the last few years for the stakeholders involved regarding the level of local, regional or national impact that an investment in transport infrastructure may have. From a decision making 
perspective the evaluation and analysis of investment proposals both during and after the planning phase of a project may prove to be quite complex for the targeted geographical areas that need to be re-developed. In most cases the ongoing interventions have long term objectives to achieve and the developed transport infrastructure aims to serve the public for many years.

Consequently, the evaluation stage of the preliminary investment proposals necessitates the consideration and employment of a number of different parameters and criteria. The selected criteria also need to reflect the different socioeconomic and environmental dimensions on which the proposed transport infrastructure is looking to make a positive impact [6]. A scenario based methodology is proposed in this paper in order to create and to assess the likely scenarios of sustainable development that a transport infrastructure investment is likely to generate and to fulfil in the future. This also heavily depends on the quantity, quality and availability of data that can help to create significant supply and demand scenarios.

\section{AREA OF INTEREST}

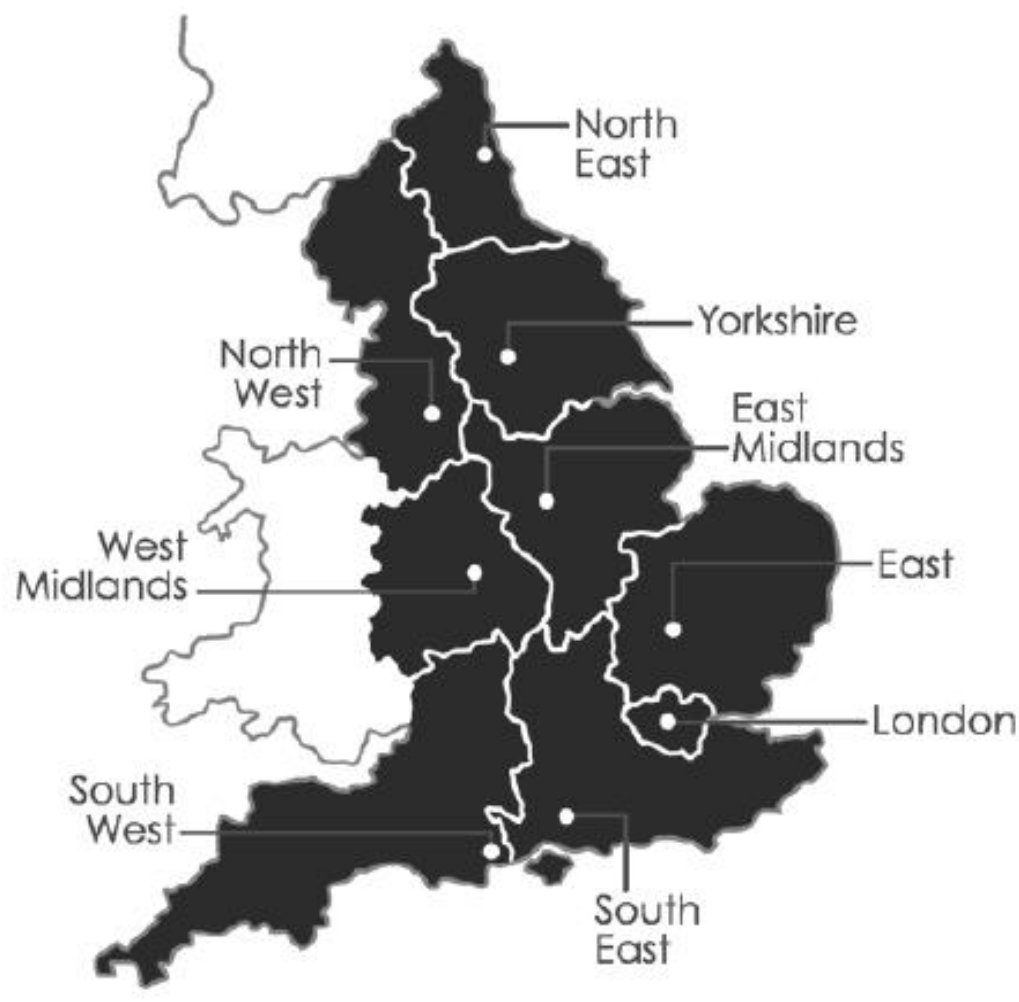

Source: Youth Dance England.

Figure 1. Regions of England

England is composed of nine regions (figure 1). These are, in alphabetical order: East, East Midlands, Greater London, North East, North West, South East, South West, West Midlands, Yorkshire and the Humber. 


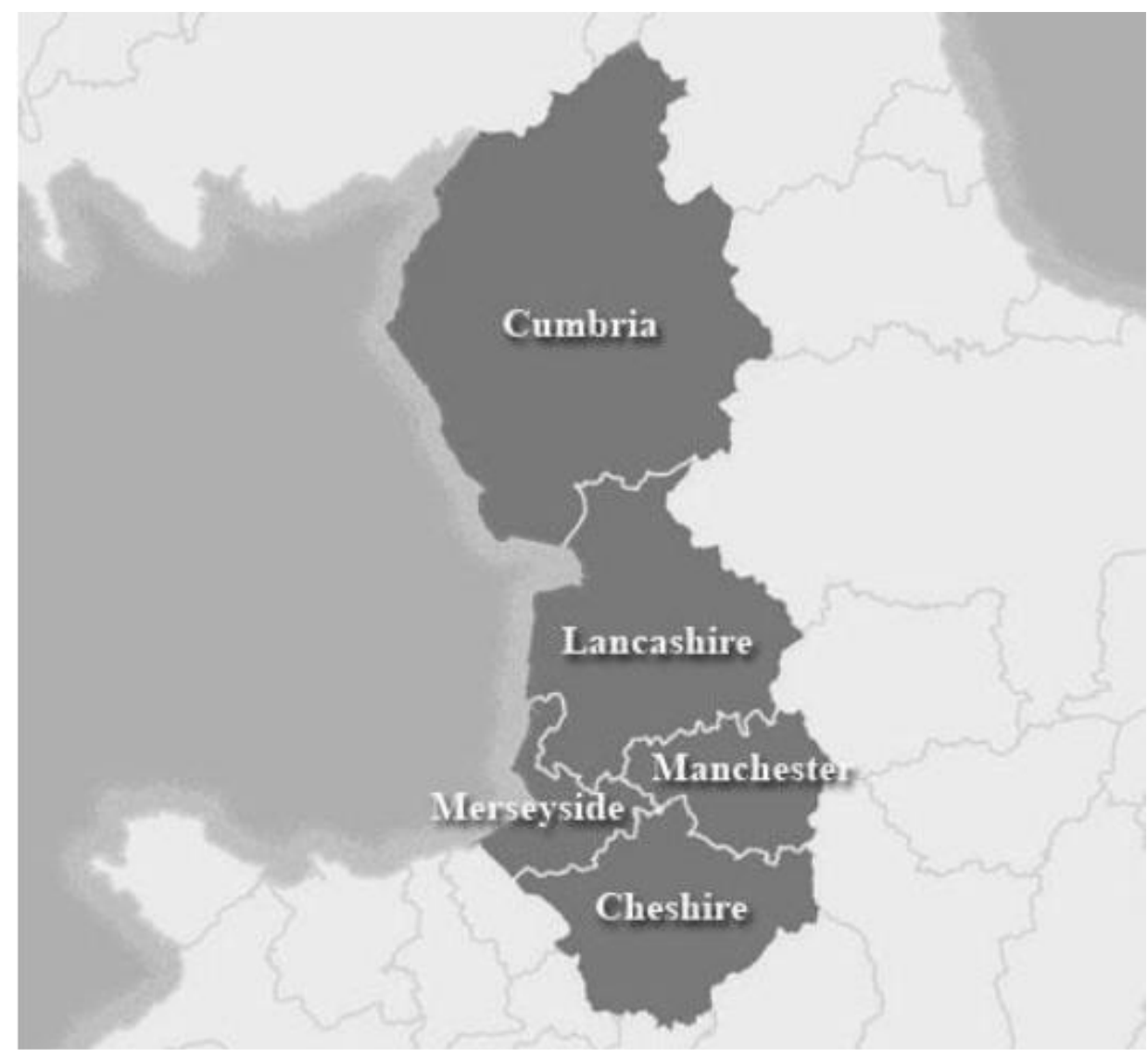

Source: PicturesofEngland.com

Figure 2. Counties of North West England

This paper focuses on North West England. As shown in figure 2 the North West of England is divided in to five counties. These are, in alphabetical order: Cheshire, Cumbria, Greater Manchester, Lancashire, and Merseyside. The counties of Cumbria, Lancashire, and Cheshire are predominantly rural whereas large urban areas cover the counties of Greater Manchester and Merseyside. According to the Office of National Statistics the population of England in 2010 was 52,234,000. Of this total number 6,936,000 (13\%) resided in the North West region of England. This made the North West the 3rd most populous region after London and the South East. Of the total population of the North West 3,983,000 (57\%) resided in the two smallest counties (Greater Manchester and Merseyside). The remaining 2,953,000 (43\%) were spread across the much larger area of Cheshire, Cumbria, and Lancashire. In 2010, the North West of England produced approximately $60 \%$ of the UK's industrial output, a significant proportion of which is exported. This makes the infrastructure of the region key to the economic well-being of the nation.

\section{METHODOLOGY FOR THE DETERMINATION OF THE IMPACT OF TRANSPORT INFRASTRUCTURE PROJECTS ON SUSTAINABLE DEVELOPMENT}

This paper provides a descriptive scenario based analysis of selected critical infrastructure projects in the region of North West England. The survey tool used enabled participants representing the broad demographic of the region to be brought together to form a focus group. The aim of this group was to identify critical infrastructure projects within the area of interest of this paper and provide information regarding the current status of these projects. Investigations of this nature can have difficulty identifying suitable indicators to provide an effective assessment of the sustainability of a selected project. For this paper a list of universal indicators were identified to enable the assessment of future change scenarios within the regional logistics gateway of North West England. 
The proposed methodology consists of the following five steps:

Step 1: Description of the project, its location and time frame, current status, funding scheme, level of modal interoperability, synergies within its region and level of usefulness.

Step 2: SWOT analysis.

Step 3: Identification of bottlenecks, areas of pressure and levels of congestion.

Step 4: Overview of co-modality based scenarios for a specific priority project for the 2030 Horizon.

Step 5: Modelling of scenarios in the form of radar charts based on a multi criteria analysis impact model originating from the main drivers of change for future transport systems.

Step 6: Dissemination of results and follow up workshops with regional stakeholders.

The fifth step of this methodology supports the sustainability scenarios' analysis by providing a comprehensive list of indicators and sub-indicators in the areas of policy, demography and society, energy and environment, technology and transport chain, economics and finance and risk management. The objective of this methodology is not only to identify the critical infrastructure projects in the area of interest but also to perform a sustainability assessment of these projects using an integrated model which takes into consideration the performance dynamics of an infrastructure project against the various identified economic, social and environmental dimensions. The use of the indicators' based model in this paper introduces a novel approach for the assessment of future scenarios for sustainable development. The proposed scenarios' analysis provides some insights into the evaluation of selected critical transport infrastructure projects in a particular area of interest within the examined region. The selection of appropriate performance indicators allows a range of infrastructure projects to be assessed. The analysis of the resultant data can be used to suggest the likely impact of a given project on the sustainable development of its host region [7]. The approach also employs a universal assessment of the interrelationships between the parameters on a project's sustainability performance. This allows a better understanding to be developed of how sustainable development scenarios can more readily be realized. The improved level of insight that results from this can be used to identify when corrective action needs to be taken to address the situation when the likely performance of a project is expected to be unsatisfactory.

\section{INTEGRATED ASSESSMENT OF CRITICAL TRANSPORT INFRASTRUCTURE PRIORITY PROJECTS AND SCENARIOS FOR SUSTAINABLE DEVELOPMENT}

A consensus is required as to how an indicators' based methodology can best serve the transnational activity on selected priority projects both geographically and modally. A central requirement for the selection of the critical infrastructure projects under investigation is their contribution to the sustainable development of a transportation system as illustrated in figure 3 . Also the transnational and international elements need to be taken into consideration during the selection process as regional integration into a regional transport network. How a project is funded is another important selection factor since the return on the investment ratio needs to be above average not only in financial terms but also against all dimensions of sustainable development.

Within this context the introduced methodology also allows the use of a GIS Geodatabase in order to explore further the selected projects' territorial cohesion and interrelationships. For logistics services to be competitive the infrastructure on which they operate must be sufficient to allow the services provided to be of high quality [8].

In addition to the theoretical dimensions of quality the technical principles of interoperability between different modes of transport must be maintained. Whether consignments are transported by sea or road, they should be able to be loaded onto other modes of transport such as rail and inland waterways. Some of the available literature has raised the issues of quality and 
interoperability and has also looked into providing solutions that facilitate greener transport through modal shift. This is very important as the quality and efficiency of the whole intermodal transport chain relies on the ability of every mode to individually perform to a high standard when required. Another area of concern is the availability of accessible data (Wang and Walden, 2004). In some cases there is a complete absence of data whereas in others there is a mass of data which is all but unintelligible to anyone but those who compiled it. The availability of accessible data is very important as research findings will often contribute towards policy formulation and will therefore need to be validated through the original source data. Predicting the requirements for future transport infrastructure and measuring the level of usefulness that developments will have in the long term becomes a problem when no universal indicators are available for measurement.

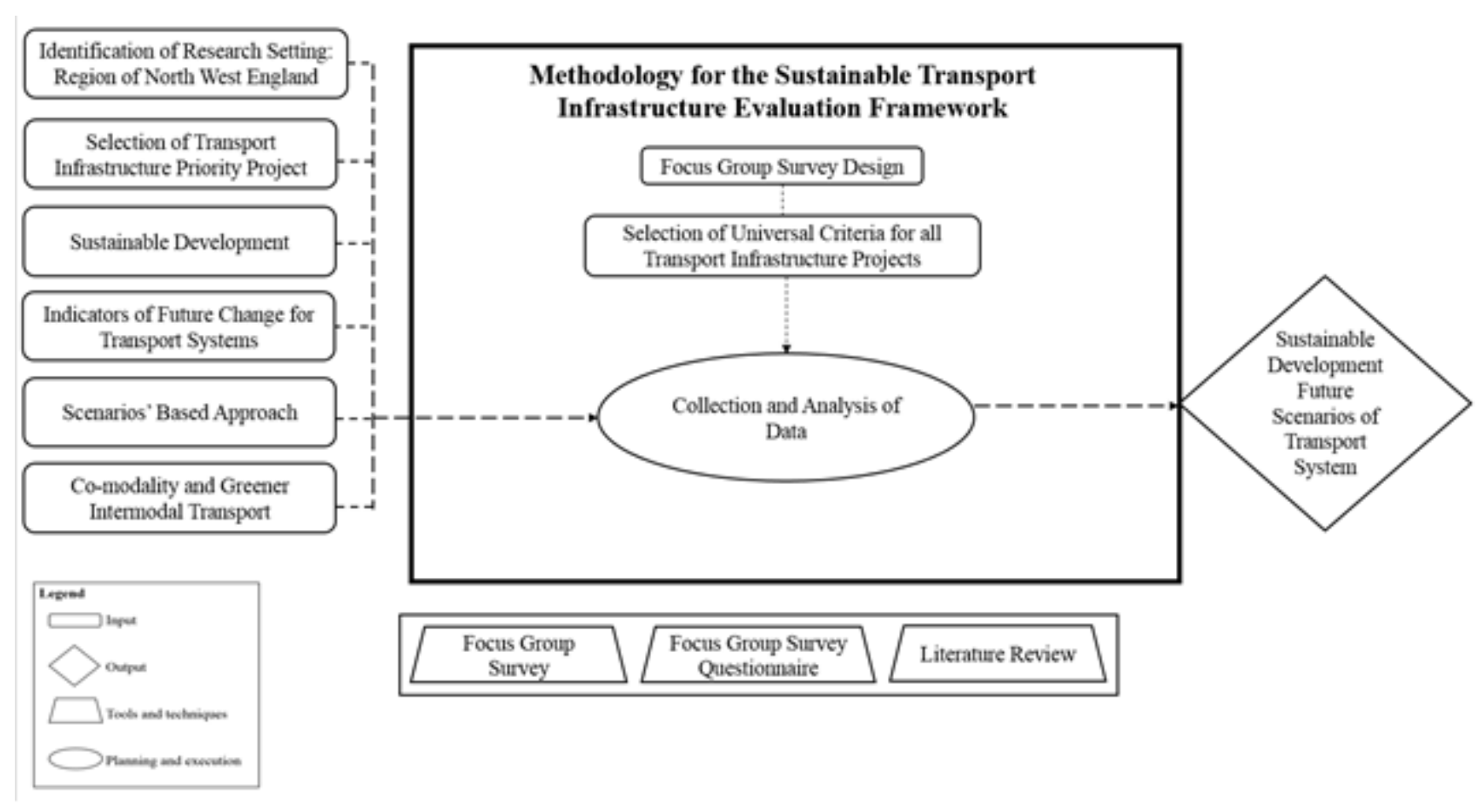

Source: Own

Figure 3. Sustainable transport infrastructure projects evaluation framework

\section{A. Focus group survey instrument design}

After carrying out a desktop literature review on existing methodologies of scenario creation and the sustainable development of transport a survey template was designed and produced. It was concluded that a comprehensive but user friendly template would enable the participants of the focus group to identify infrastructure projects in the North West region of England and assess them against a set list of criteria. The template was designed to assist the respondents in gathering and organizing the available information for the schemes that they believe to be of high importance to the region under examination. This universal methodology allows for the transnational application of the data collection tool across different regions with no restrictions.

The questionnaire used consists of five parts that are designed to allow detailed information to be collected on selected transport infrastructure projects. The first part of the template is for information regarding a project's nature and character, its description and geographical location, the projected time frame of the development, current status, economic background of the scheme (including who is financing the project and its estimated budget), modes of transport which interact with the specific infrastructure, any synergies with other regions, environmental impacts and likely benefits that the project will bring to the area. 
The second part of the template is a Strengths, Weaknesses, Opportunities and Threats (SWOT) analysis. This is used to uncover significant facts regarding the core competencies of the scheme with respect to modal shift and greener transport solutions. This section allows the detection of any possible weaknesses and threats that could prevent the project from achieving its objectives. The third part of the template looks into the existing bottlenecks that a project is looking to remove or reduce. This analysis complements the analytical framework as it enables the participants to identify existing areas of congestion that are affecting the proper functioning of the existing transport network.

Part four and five of the template complete the transport infrastructure evaluation framework by providing a scenario planning context for the year 2030. In part four, participants are asked, based on the available information, to justify the decision that they took to include a project in the investigation process and establish its potential to improve the performance of the existing transport network.

In part five a six point scoring system is used to determine the likely impact that each project is expected to have. The impact is measured against a number of sub criteria that are linked to the established six main categories of drivers of change for future transport [9]. The results are then displayed in the form of a radar chart.

For the specific needs of this survey the following categories of indicators and sub-indicators were identified:

- Policy: Governance, Sustainable development, Regulation and Taxation.

- Demography \& Society: Population growth, Employment, Retirement, Urbanisation and Changing work patterns.

- Energy \& Environment: Carbon emissions, Air quality, Natural Environment, Heritage, Landscape and Noise.

- Technology \& Transport chain: Information technologies, Congestion, Traffic Management, Capacity, Connectivity, Interoperability and Modal Shift.

- Economics \& Finance: Economic growth, Global trade, Regional Development and Transportation Costs.

- Risk Management: Reliability and Resilience.

As shown in figure 4 all of these factors play a role both individually and collectively. The element of interconnection between these factors allows them to be used to analyse the impact of a given development. Consequently the possible future state of the wider regional transportation system can be inferred. 


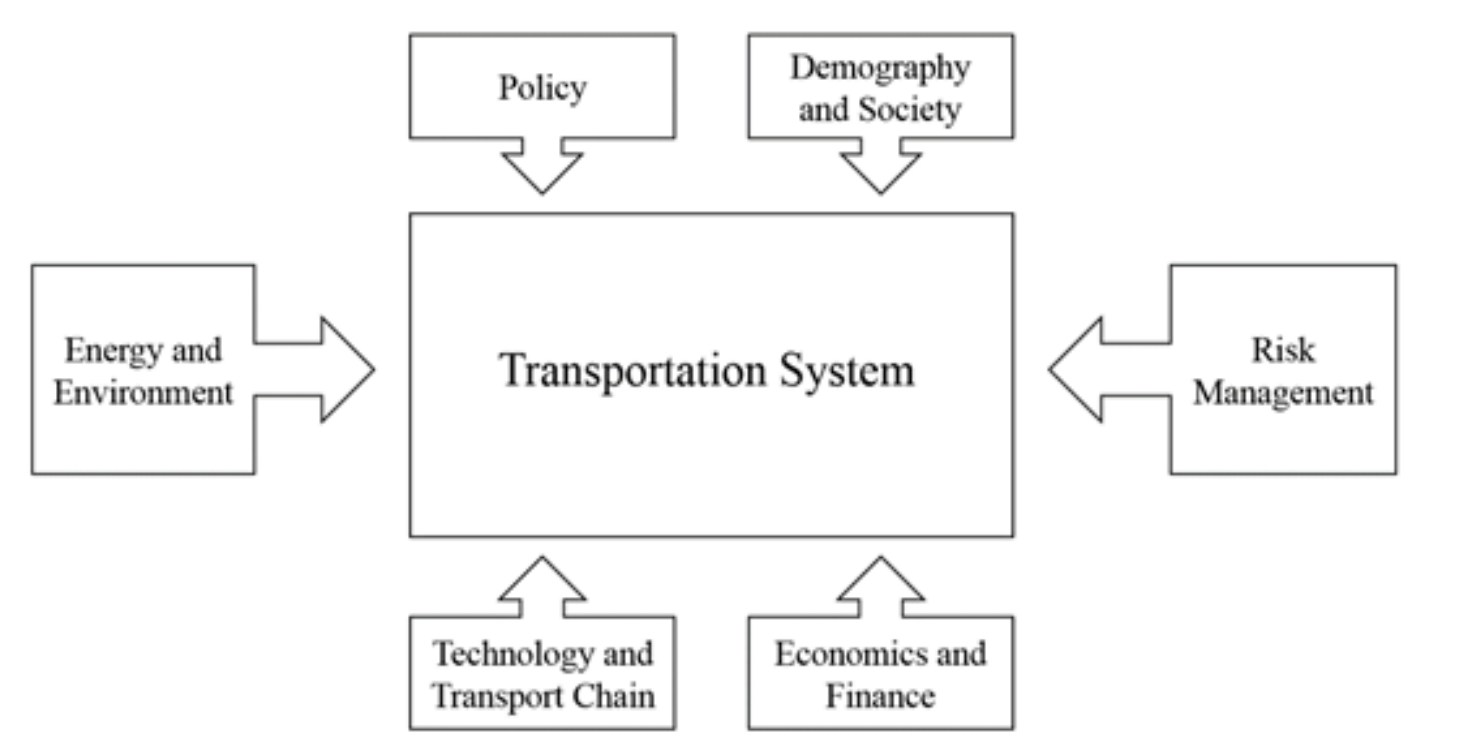

Source: Own

Figure 4. Structure and dynamics of a regional transportation system

\section{B. Selection and organisation of a focus group}

The creation of a focus group was an important part of the overall process of analyzing infrastructure projects in the region. It was through this group that detailed information and insight was be gathered. To achieve this the focus group was constructed of participants that were representative of a cross section of the demographic of North West England. This allowed a selection process to be followed that identified a range of different existing and planned transport infrastructure projects.

\section{Selection of a critical transport infrastructure priority project}

Intermodal transport is not just a concept or business practice it is also a service. Moreover, it is a very complex service that requires the different modes of transport to be operating in close conjunction with each other. The future will be very challenging as the demand for transport and logistics services is set to increase. Also, the expectations of the users of these services will remain high. Sustainable intermodal freight transport needs to be developed further as its infrastructure is still underutilised or in the worst cases not capable of handling the expected increase in demand (Antoniou et al., 1997). Energy costs are on the rise and increasing $\mathrm{CO}_{2}$ emissions are making the evaluation and prediction of future scenarios a necessity. More specifically, these scenarios will be required to take a closer look at supply and demand based issues.

Data was provided by the participants of a focus group to identify different infrastructure development projects within the North West region of England. Although at a first glance the findings were very encouraging for the region it is accepted that a more thorough analysis of the data provided needs to be performed in order to validate these scenarios. Participants of the focus group were asked to identify, according to the best of their knowledge, a limited number of transport infrastructure projects in their area of interest. An example of a selected transport infrastructure project is described below along with the findings of the focus group survey regarding its current and future impact in the region's sustainable development: 
The Manchester Ship Canal is an inland waterway in the North West of England. It is 36 miles (58 $\mathrm{km}$ ) long (Kader, 1997). Starting at the Mersey Estuary, near Liverpool, it follows the former route of the River Mersey and the River Irwell. This takes the canal through the county of Cheshire and the county of Lancashire. The aim of this project is to create of a fully integrated logistics platform that more effectively combines the Port of Liverpool and the Manchester Ship Canal. This will stretch from Liverpool 2, the new deep-water container terminal on the River Mersey, into the heart of Manchester and it will allow the benefits of the new terminal to be closely felt by both of the most population dense counties in the North West of England. A number of additional logistics hubs will be developed along the ship canal. These will include sites at Port Bridgewater, Warrington and Port Salford. Currently the project is ongoing and is funded both from the private and the public sector. In total it is expected that over the next 50 years the project will represent a £50billion investment in the region.

\section{SWOT analysis with an emphasis on congestion and modal shift}

One of the main advantages of this inland waterway project is that it links the deep water services at Liverpool 2 to inland distribution and manufacturing facilities along the length of the ship canal. It also offers opportunities reduce carbon emissions and potentially provide a cheaper alternative to the haulage of freight inland by road.

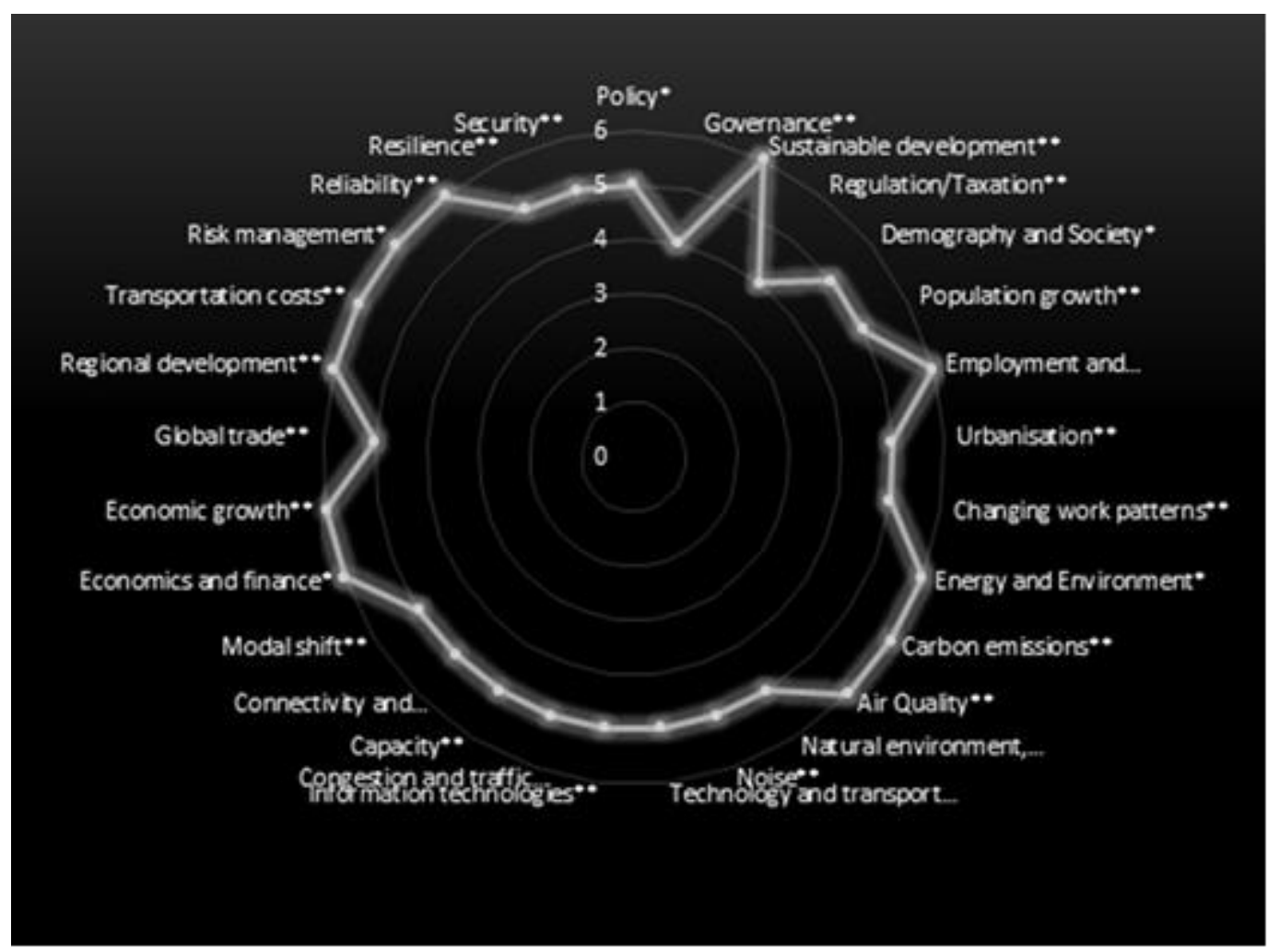

Figure 5. Radar chart representation of future growth scenario of sustainable development for the inland waterways transport project

Bottlenecks that the project aims to reduce in the region

Ten motorways are within ten miles of this integrated waterway. However, the port of Liverpool is linked directly to the British rail network and operates up to nine ferry services a day to Ireland. As a result, it is expected that this project will, upon completion, be able to offer a greener alternative to the motorway network. 
Overview of co-modality and growth scenarios for 2030

Upon its completion, this project has the potential to achieve a high impact on the development of co-modality in the region. It is expected that modal shift will be achieved by the promotion of greener shipping and improved connectivity to intermodal facilities across the United Kingdom.

\section{Sustainable development scenarios for 2030}

Figure 5 shows the scores allocated by the focus group during the evaluation process for the Manchester Ship Canal project. This provides an overview of the significant impact scenarios that the project is likely to generate by the year 2030.

\section{FOCUS GROUP IMPACT SURVEY}

To measure the impact of the focus group a quantitative methodology was adopted. Before and after attending the focus group the attendees were asked to rate, on a scale of 1 (minimum) to 5 (maximum), their level of agreement with the following statements:

1. I know which infrastructure my company uses for its freight movements.

2. I am confident that my company uses the most appropriate infrastructure for its freight movements.

3. I believe that my company's current choice of infrastructure use could be improved.

4. I am aware of the upcoming developments within the Port of Liverpool / Manchester Ship Canal corridor.

5. I believe that the development within the Port of Liverpool / Manchester Ship Canal corridor have the potential to bring transformational change to the North West region of England.

The responses to these statements were compiled and used to identify whether the focus group had any impact on the eleven people that attended.

1. I know which infrastructure my company uses for its freight movements.

Prior to the focus group, attendees were very confident (4.3/5.0) that they knew which infrastructure their companies used for their freight shipments. This improved after the focus group (4.5/5.0) but only by a small margin. The limited nature of this increase and the very similar distribution of responses suggest that the event had a negligible impact in this regard.

2. I am confident that my company uses the most appropriate infrastructure for its freight movements.

Prior to the focus group, attendees were very confident $(4.2 / 5.0)$ that their companies were using the most appropriate infrastructure for their freight movements. After the focus group this was less so (3.1/5.0). In many cases an increasing element of doubt had begun to enter the minds of the attendees. This is a noteworthy development as they will now have a more open mind with regards to the sustainability of their companies transport operations.

3. I believe that my company's current choice of infrastructure use could be improved.

Prior to the focus group, most of the attendees believed that their company's choice of infrastructure use was good (1.9/5.0) and that it would be difficult to improve upon it. After the event many of the attendees had a more open mind to the possibility that their companies could make more sustainable choices when it came to their freight transportation activities $(3.9 / 5.0)$. 
4. I am aware of the upcoming developments within the Port of Liverpool / Manchester Ship Canal corridor.

Prior to the focus group, many of the attendees stated that they were unaware (1.9/5.0) of the upcoming developments proposed for the Port of Liverpool / Manchester Ship Canal corridor. A wide range of reasons were offered to explain this but it was also suggested by some attendees that others may have feigned their lack of awareness to avoid giving away anything about their businesses activities. Despite this, after the focus group, all of the attendees had a much greater understanding (4.8/5.0) of what was planned for the Port of Liverpool / Manchester Ship Canal corridor.

5. I believe that the development within the Port of Liverpool / Manchester Ship Canal corridor have the potential to bring transformational change to the North West region of England.

Prior to the focus group, there was a definite lack of confidence (1.7/5.0) that the proposed developments would have the potential to bring transformational change to the North West region of England. This could be explained by the attendee's lack of understanding (identified in question four) of what these developments actually entailed. After the focus group, the attendees had a much greater understanding of what was planned (question 4) and many of them (3.1/5.0) could see the potential of what was being proposed. However, some still needed further convincing on the projects ability to deliver transformational change to the region.

\section{Radar Chart plot of the Impact Survey Results}

Radar Charts are a useful way of allowing comparisons to be made between the group's pattern of thought before and after its constituent members attended the focus group. There are two clearly defined patterns:

- The 'before' attending pattern, where attendees show a high level of understanding of the infrastructure which their companies utilise and a high level of confidence in it being the most suitable choice. This is accompanied by a limited understanding of the upcoming developments in the Port of Liverpool / Manchester Ship Canal corridor.

- The 'After' attending pattern, where attendees show a high level of understanding of the infrastructure which their companies utilise but a lower level of confidence in it being the most suitable choice. This is accompanied by a greater level of understanding of the proposed developments in the Port of Liverpool / Manchester Ship Canal corridor but some degree of uncertainty as to whether this will deliver what it promises.

Comparing these patterns suggests that attendees left the meeting of the focus group with a more critical opinion of the transport choices made by their companies and an increased understanding of one of the largest infrastructure projects to be undertaken in the North West region of England over the next few years. 


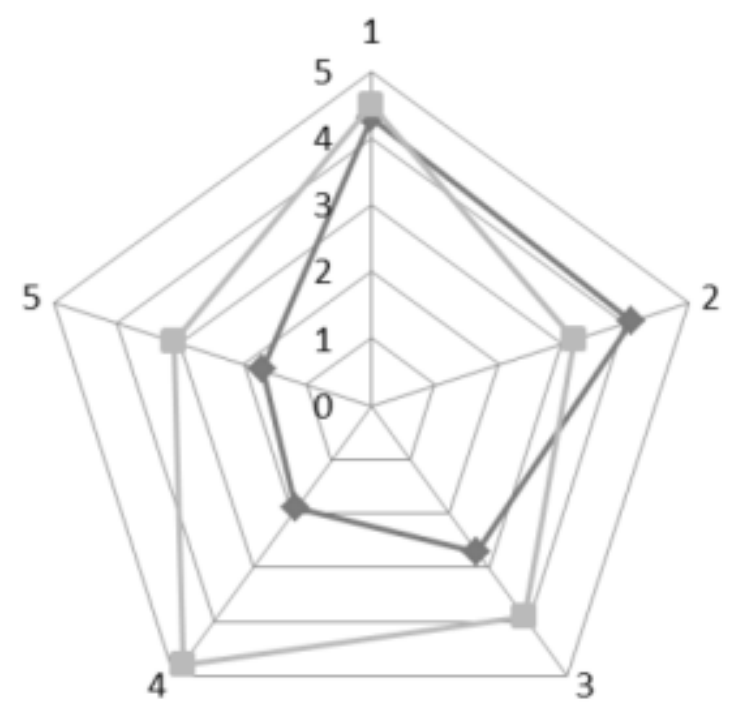

$\multimap$ Before Workshop

After Workshop

Figure 6. Radar chart demonstrating the impact of this event

\section{CONCLUSIONS}

The focus group that took place identified a list of existing and planned transport infrastructure projects in North West England. From its findings it could be seen that the identified transport infrastructure projects are expected to have a medium to high impact on the sustainable development of the region. The majority of these projects have as an objective the elimination of bottlenecks in the transport network, the enhancement of modal shift opportunities and a positive contribution to sustainability. This paper covers the methodology followed to identify these projects along with their evaluation in terms of their impact on sustainable development. The methodology allowed the collection of useful qualitative data on the background, location and objectives of each project. It also allowed for the collection and analysis of quantitative data that led to the creation of a number of future scenarios. By examining the impact on sustainable development that will likely result from a specific infrastructure project (i.e. that of the Manchester Ship Canal project). This paper demonstrates that a scenario based development methodology is a feasible method for identifying potential scenarios that may arise within a given region as a result of the development of its transport infrastructure.

\section{REFERENCES}

1. Amekudzi, A.A., Thomas-Mobley, L. and Ross, C.L. (2007) Transportation planning and infrastructure delivery in major cities and megacities. Transportation Research Record 1997, pp. 17-23.

2. Wassalo, W, (2008) Co-modality, a new buzz-word in the logistics field?, KOMODA project, The Logistics 2008 Congress, Poland.

3. Zografos, K.G.and Regan, A (2004) Current challenges for intermodal freight transport and logistics in Europe and the US. Journal of the Transportation Research Board, Vol. 1873, pp. 7078.

4. Bury A., Paraskevadakis D., Wang J., Ren J., Bonsall S., (2014), Workshops report for Significant Transport Infrastructure and its impact on the Sustainable Development, EU project Weastflows Technical Report 2.5, Liverpool John Moores University, UK.

5. Day, R.H. and Zou, G. (1994) Infrastructure, restricted factor substitution and economic growth. Journal of Economic Behaviour and Organization, Vol.23, pp. 149-166.

6. Rees, J. (2005) Trans-European networks: EU Infrastructure proposals Research in Transportation Economics, Vol.15, pp.67-73. 
7. Paraskevadakis D., Bury A., Wang J., Ren J., Bonsall S., (2014), Modelling of sustainable development scenarios for logistics and transport systems in NW Europe, EU project Weastflows Technical Report 2.3, Liverpool John Moores University, UK.

8. Rodriquez JP. (2010) Maritime Transportation: Drivers for the Shipping and Port Industries, OECD International Transport Forum.

9. Bowersox, D.J., Closs, D.J. and Cooper, M.B. (2006) Supply Chain Logistics Management, second ed. McGraw-Hill Publishing, New York.

10. Jin, M., Wang, H. and Walden, C. (2004) System performance measures for intermodal transportation with a case study and industrial application. National Center for Intermodal Transportation: A partnership between the University of Denver and Mississippi State University.

11. Antoniou, C., Ben-Akiva, M.E., Bierlaire, M., and Mishalani, R. (1997) Demand Simulation for Dynamic Traffic Assignment. Proceedings of the $8^{\text {th }}$ IFAC/IFIP/IFORS symposium on transportation systems.

12. Kader, A. (1997) Cost modeling for inland waterway transport systems, A thesis submitted in partial fulfilment of the requirements of Liverpool John Moores University for the degree of Doctor of Philosophy. Liverpool: Liverpool John Moores University.

\section{AUTHORS (* CO-FIRST AUTHORS)}

A. Dimitrios PARASKEVADAKIS* is with the Logistics, Offshore and Marine Research Institute (LOOM) at the School of Engineering and Maritime Operations in Liverpool John Moores University as a research associate and an MSc and PhD holder specialising in operations management and service quality of freight transport for businesses. He has years of experience in managing EU research projects in the field of transport and supply chain logistics. His research interests are in the areas of intermodal transport chains, logistics gateways, maritime and supply chain clusters, education and training (email: d.paraskevadakis@ljmu.ac.uk, d.paraskevadakis@aol.co.uk).

B. Alan BURY* is with the Logistics, Offshore and Marine Research Institute (LOOM) at the School of Engineering and Maritime Operations in Liverpool John Moores University. He also sits on the overview and scrutiny committee for the Association of Greater Manchester Authorities (AGMA). Formerly an officer in the Merchant Navy and a consultant on infrastructure projects. $\mathrm{He}$ is now a Lecturer in Maritime Operations and also a PhD candidate with current research interests in modal choice and North West England's Atlantic Gateway (email: a.bury@ljmu.ac.uk).

C. Prof. Jin WANG is the director of the Logistics, Offshore and Marine Research Institute (LOOM) at the School of Engineering and Maritime Operations in Liverpool John Moores University. Prof. Wang specializes in design and operation of maritime engineering systems such as ships, offshore installations and port terminals (email: j.wang@ljmu.ac.uk).

D. Dr Jun REN is with the Logistics, Offshore and Marine Research Institute (LOOM) at the School of Engineering and Maritime Operations in Liverpool John Moores University and is a Reader in Logistics and Supply Chain Management (j.ren@ljmu.ac.uk).

E. Dr Stephen BONSALL is with the Logistics, Offshore and Marine Research Institute (LOOM) at the School of Engineering and Maritime Operations in Liverpool John Moores University and is a Senior Lecturer in Maritime Operations (s.bonsall@ljmu.ac.uk).

F. Prof. Ian JENKINSON is the director of the School of Engineering and Maritime Operations in Liverpool John Moores University. He has an active interest in supporting manufacturing in the region, and has developed strategic links to support training and applied research in the engineering and maritime sectors (email: i.d.jenkinson@ljmu.ac.uk). 